\title{
BLOOD PRESSURE LEVELS AND RISK FOR BREAST NEOPLASIAS
}

\author{
André Chaves Calabria', Inara Regina Frühauf1 \\ ${ }^{1}$ Universidade do Planalto Catarinense - Lages, (SC), Brazil.
}

Introduction: Breast cancer (BC) is one of the most prevalent cancers and considered one of the main causes of death among women worldwide. The genetic contribution to the incidence of $\mathrm{BC}$ is of great relevance, however, modifiable risk factors seem to be related to the development of this neoplasm. Several studies have provided evidence on the role of blood pressure (BP) levels in the carcinogenesis process. Goals assess the association between BP levels and the occurrence of BC. Methods: This is a case-control study nested in a cohort conducted between December 2013 and August 2014 in a municipality in the south of Brazil. Patients referred to oncology referral centers before starting adjuvant or neoadjuvant therapy for $\mathrm{BC}$ participated in the study. The control group was composed of women who visited the gynecology clinic during the same period. For each newly diagnosed case of BC, a control matched for age ( \pm 5 years) and menopausal status was included. Data were obtained through measurements with standardized techniques of BP levels and waist circumference (WC) measurement. Individuals with systolic BP $\geq 130 \mathrm{mmHg}$ and/or diastolic $\mathrm{BP} \geq 85 \mathrm{mmHg}$ were considered to have altered blood pressure. Results: Eighty two patients with BC and 82 controls $(n=164)$ were evaluated. Slightly different characteristics were found between the two groups: skin color $(\mathrm{p}=0.097)$, months of breastfeeding $(\mathrm{p}=0.185)$ and physical activity $(\mathrm{p}=0.160)$. These variables were included in the adjusted analysis. Regarding the BP measurement, patients with SBP $\geq 130 \mathrm{mmHg}$ and with DBP $\geq 85 \mathrm{mmHg}$ were 7.30 and 4.56 times more likely to have MF (Malignant), respectively (95\%CI 2.43-21.91, $\mathrm{p}<0.001$ and 95\%CI 1.82-11.44, $\mathrm{p}=0.003)$. This relationship remained significant after adjustment for $\mathrm{WC} \geq 80 \mathrm{~cm}(\mathrm{OR}=6.75,95 \% \mathrm{CI} 2.22-20.54$ and $\mathrm{OR}=6.75$, 95\%CI 1.67-10.81). Conclusions: The results of this study corroborate the current findings in the literature, showing evidence of an association between BP and BC levels. BP assessment, already incorporated into clinical practice and considered a predictor of several comorbidities, may gain additional importance in the female population as a modifiable risk factor for the prevention of BC. Thus, the importance of interventions in the management of $\mathrm{BP}$ levels in this population is elucidated. 